\title{
A cluster randomized controlled trial of an online psychoeducational intervention for people with a family history of depression
}

Llewellyn Mills $^{1 \dagger}$, Bettina Meiser ${ }^{1 * \dagger}$ (D, Raghib Ahmad ${ }^{1}$, Peter R. Schofield ${ }^{2,3}$, Michelle Peate ${ }^{1,4}$, Charlene Levitan ${ }^{1,5}$, Lyndal Trevena ${ }^{6}$, Kristine Barlow-Stewart ${ }^{7}$, Timothy Dobbins ${ }^{8}$, Helen Christensen ${ }^{9}$, Kerry A. Sherman ${ }^{10}$, Kate Dunlop ${ }^{11}$ and Philip B. Mitchell ${ }^{5}$

\begin{abstract}
Background: People with a family history of major depressive disorder (MDD) or bipolar disorder (BD) report specific psychoeducational needs that are unmet by existing online interventions. This trial aimed to test whether an interactive website for people at familial risk for depression (intervention) would improve intention to adopt, or actual adoption of, depression prevention strategies (primary outcome) and a range of secondary outcome measures.

Methods: In this cluster randomised trial, primary care practises were randomised to either provide the link to the intervention or the control website. Primary health care attendees were invited by letter to opt into this study if they had at least one first-degree relative with MDD or BD and were asked to complete online questionnaires at baseline and 2-week follow-up.
\end{abstract}

Results: Twenty general practices were a randomized, and 202 eligible patients completed both questionnaires. Thirtynine (19.3\%) of participants were male and 163 (80.7\%) female. At follow-up, compared to controls, the intervention group: (i) were more likely to intend to undergo, or to have actually undergone, psychological therapies $(\mathrm{OR}=5.83$, 95\% Cl: 1.58-21.47, $p=.008$ ); (ii) had better knowledge of depression risk factors and prevention strategies (mean difference $=0.47,95 \% \mathrm{Cl}: 0.05-0.88, p=.029$ ); and (iii) were more likely to accurately estimate their lifetime risk of developing BD (mean difference $=11.2,95 \% \mathrm{Cl}$ : $-16.52--5.73, p<.001$ ). There were no statistically significant betweengroup differences in change from baseline to follow up for any of the remaining outcome measures (Patient Health Questionnaire, Perceived Devaluation-Discrimination Questionnaire and Perceived Risk of Developing MDD).

Conclusion: The opt-in nature of the study may have led to participation bias, e.g. underrepresentation of males, and hence may limit generalisability to the broader population at familial risk for depression. This is the first website internationally focusing specifically on informational needs of those at familial risk of depression. Our interactive website can play an important role in improving the outcomes of individuals at familial risk for depression. Testing the intervention in other settings (e.g. psychology, psychiatry, genetic counselling) appears warranted.

Trial registration: The study was prospectively registered with the Australian and New Zealand Clinical Trials Group (Registration no: ACTRN12613000402741).

Keywords: Family history, Major depressive disorder, Bipolar disorder, Online intervention, Psycho-education

\footnotetext{
* Correspondence: b.meiser@unsw.edu.au

'Llewellyn Mills and Bettina Meiser contributed equally to this work.

${ }^{1}$ Psychosocial Research Group, Prince of Wales Clinical School, UNSW,

Sydney, Australia

Full list of author information is available at the end of the article
}

(c) The Author(s). 2019 Open Access This article is distributed under the terms of the Creative Commons Attribution 4.0 International License (http://creativecommons.org/licenses/by/4.0/), which permits unrestricted use, distribution, and reproduction in any medium, provided you give appropriate credit to the original author(s) and the source, provide a link to the Creative Commons license, and indicate if changes were made. The Creative Commons Public Domain Dedication waiver (http://creativecommons.org/publicdomain/zero/1.0/) applies to the data made available in this article, unless otherwise stated. 


\section{Introduction}

The strongest risk factor for developing depression is having a history of depression in the family [1]. Adoption, twin, and family studies suggest that major depressive disorder (MDD) and bipolar disorder (BD) are both highly heritable conditions [2] with heritability estimates of around $40 \%$ for MDD [1, 3] and $80 \%$ for BD $[4,5]$. A recent meta-analysis showed that having one first-degree relative (FDR) with MDD more than doubles the risk of developing depression compared with having no FDRs with MDD $(\mathrm{OR}=2.1)$ [6]. With two FDRs the risk is triple that of individuals with no family history of MDD $(\mathrm{OR}=3.2)[6]$. The same meta-analysis found that having a single FDR with BD increased the risk of developing BD by almost eight times $(\mathrm{OR}=7.9)$ [6].

As a consequence of these relative risk estimates, many individuals with a family history of MDD or BD are frequently concerned about their own and their offspring's future risk of developing these disorders [7]. Unfortunately they also report that their educational and psychological support needs in relation to their perceived familial risk are largely unmet by currently available psychoeducational resources [8]. The principal need expressed by people at familial risk for MDD or BD is for reliable information, concerning: (i) what causes the disorders to develop; (ii) how to recognise symptoms; (iii) the risk of their current or future offspring developing the disorders; (iv) strategies for reducing risk of developing the disorders; and (v) their individual genetic risk of developing the condition based on family history $[8,9]$.

Psychiatric genetic counselling is an intervention well suited to meet these needs. It has been found to increase empowerment [10], risk perception accuracy and knowledge [11, 12]; decrease a sense of stigma [12]; and help people with psychiatric disorders and their families to understand the causes of their illness, thus enabling them to adapt more successfully. However, psychiatric genetic counselling is a very new speciality and qualified practitioners are exceedingly rare across the world, and as such innovative approaches are required to meet the needs of people at familial risk for depression and other psychiatric disorders. One very cost-effective strategy that seems well suited to meet the needs of people at familial risk is psycho-education provided through the internet.

The internet is arguably the most efficient way of reaching a large number of individuals across a wide range of geographic and economic settings, and for many is the preferred method of accessing mental health information [8]. It also allows for the delivery of information tailored to the individual user (e.g. personalised risk assessments). Websites that improve depression literacy and/or deliver online therapeutic techniques have been shown to be effective at reducing the symptoms of depression [13-16]. There are several high-quality websites available in Australia that fulfil this function (e.g. www.beyondblue.org.au, www.bluepages.anu.edu.au, https://moodgym.anu.edu.au); however none are targeted specifically at those with a family history of depression.

The information most desired by individuals with a family history of MDD or BD relates to strategies that they or their offspring might use to reduce the risk of onset of depression $[8,9]$. There is strong evidence from meta-analyses that prevention trials can be very effective at reducing the likelihood of occurrence of new cases of depression [17, 18]. For those with a familial risk of developing depression, psychological therapy, especially cognitive behavioural therapy, has been shown to be particularly effective at preventing depression [17, 19-22], almost halving the risk of its development in at-risk groups [17, 21-24]. Other factors have been shown to reduce the risk of developing depression, including: (i) regular physical activity [25]; (ii) minimising intake of alcohol (in heavy drinkers) and street drugs [26]; (iii) adequate amounts of sleep [27]; (iv) a 'Mediterranean' diet [28]; (v) adequate amounts of vitamin D [29]; (vi) good social support [30]; (vii) being optimistic [31]; and (vii) being religious and/or spiritual $[32,33]$. Though the evidence for these strategies is not as strong as for psychological therapies and regular exercise, all have been shown to be associated with a reduced risk of developing depression in at least one study, albeit ranging in terms of methodological rigour. It is vital that at-risk individuals have an easy and effective way of accessing this information to help them decide which strategies to adopt in order to reduce their risk of developing depression.

Online psychoeducational interventions have also proven effective at reducing the stigma surrounding depression [34], and there is evidence that having a genetic explanation for depression can reduce the perceived stigma surrounding the disorder [35]. By providing information about the familial basis for depression, an online psychoeducational tailored intervention may help reduce perceived stigma and encourage those with a family history of depression to adopt strategies for reducing depression risk.

Individuals with a family history of depression have specific psychoeducational needs that are not currently met by existing websites. Given the proven efficacy of online psychoeducational interventions and their potential for reaching a large number of individuals, the benefits of developing a website targeted specifically at those with a family history of depression could be substantial. The primary health care setting is perhaps the most pertinent setting to reach those with a family history of MDD or BD to meet their psychoeducational needs, given the high prevalence of these conditions in patients attending primary care physicians; the prevalence of MDD has been found to be as high as $13.9 \%$ and that of 
BD $1.9 \%$ in one study conducted in the primary care setting [36]. Therefore, this study aimed to evaluate, in the primary care setting, whether a novel interactive online psychoeducational intervention targeted at individuals with a family history of MDD of BD was more effective than written information alone at: (i) increasing intention to adopt or actual adoption of strategies to reduce risk of developing depression (primary outcome variable); (ii) lowering levels of depression symptoms; (iii) lowering perceived stigma surrounding mental illness; (iv) improving knowledge of genetic and environmental risk factors for depression; and (v) improving the accuracy in estimating risk of developing depression.

\section{Methods}

\section{Design}

This cluster randomised controlled trial took place in a general practice (primary health care) setting in Sydney, Australia. General practitioners (GPs) are routinely the first health professional contacted by individuals seeking help for mood disorders, with over $90 \%$ of Australians visiting a GP at least annually [37]. Thus general practices were deemed a suitable setting in which to access those at risk of developing depression. Care in these practices is often provided by several GPs. The study design is presented in Fig. 1. The study used a cluster randomised trial design. Randomisation to either the control or intervention condition took place at the general practice level, rather than the individual patient or the individual GP level, so as to optimise use of the intervention and to reduce possible sources of contamination (e.g. via communication between participants in different conditions attending the same practice, communication between GPs in the same practice assigned to different conditions, or via differing approaches of individual doctors to patients assigned to different conditions).

\section{Sample size}

The desired sample size for the study was 240 participants in 20 clusters, randomizing ten clusters each in the intervention and the control arm, with an average of 12 participants per cluster. These sample and cluster sizes were based on an assumed intra-cluster correlation coefficient (ICC) of 0.06 for patients within the same practice, consistent with ICCs observed for psychological variables in GP studies [37]. This would yield $80 \%$ power to detect a difference of $22 \%$ in the proportion intending to undertake risk-reducing strategies from a baseline proportion of $50 \%$ [38]. This proportion corresponds to a medium effect size, the minimum deemed to be of public health and clinical significance. To achieve the desired average per-practice sample size, allowing for attrition, up to 500 invitations per practice were sent $(10,000$ in total), based on the assumption that $20 \%$ of all individuals have at least one FDR with either MDD or $\mathrm{BD}$, and that, of these, approximately $15 \%$ would opt-into the trial [39].

\section{Participants \\ Recruitment of GP practices}

GP practices selected for invitation to participate were chosen from across greater Sydney to be as geographically and socioeconomically diverse as possible. Practices were identified using an existing GP database. GPs were sent letters of invitation and were offered a AUD\$1500 reimbursement per practice and 40 Continuing Medical Education points for each participating GP in the practice as an acknowledgement of the time commitments required to participate in the study. Those practices/GPs who returned an expression of interest form were contacted to arrange a meeting to discuss the study. The research team provided personalized academic detailing, which included an explanation of the study materials and obtained written consent from individual GPs within the practice to participate.

\section{Recruitment of patients}

Patients were eligible for inclusion in the study if they: (i) had a family history of at least one FDR with MDD or $\mathrm{BD}$; (ii) were able to give informed consent; (iii) were proficient readers in English; (iv) were aged between 18 and 75 years, and (v) had attended the practice in the past 2 years. As many GPs do not elicit and systematically record a family history of depression, patients were asked to self-identify as having a FDR with MDD or BD. Both individuals who had experienced an episode of MDD or $\mathrm{BD}$, and those who had not, were eligible to participate.

\section{Materials and measures Interventions Intervention}

A psychoeducational website (LINKS http://links.neura.edu.au) targeting people with a family history of depression was developed based on the findings from a previous study on the educational needs of individuals with a family history of depression [8] and in consultation with a multidisciplinary committee with expertise in psychiatry, psychiatric genetics, psychology, general practice, e-medicine in the psychiatry setting, genetic counselling, and genetics education. The website includes information on both the risk factors associated with developing depression (with information on the likelihood of depression occurring, early signs and symptoms of depression, environmental risk factors such as stress and lifestyle, genetic risk factors) and evidencebased strategies for reducing risk of developing depression (psychological therapy, regular physical activity, getting adequate amount of sleep, Mediterranean-style 


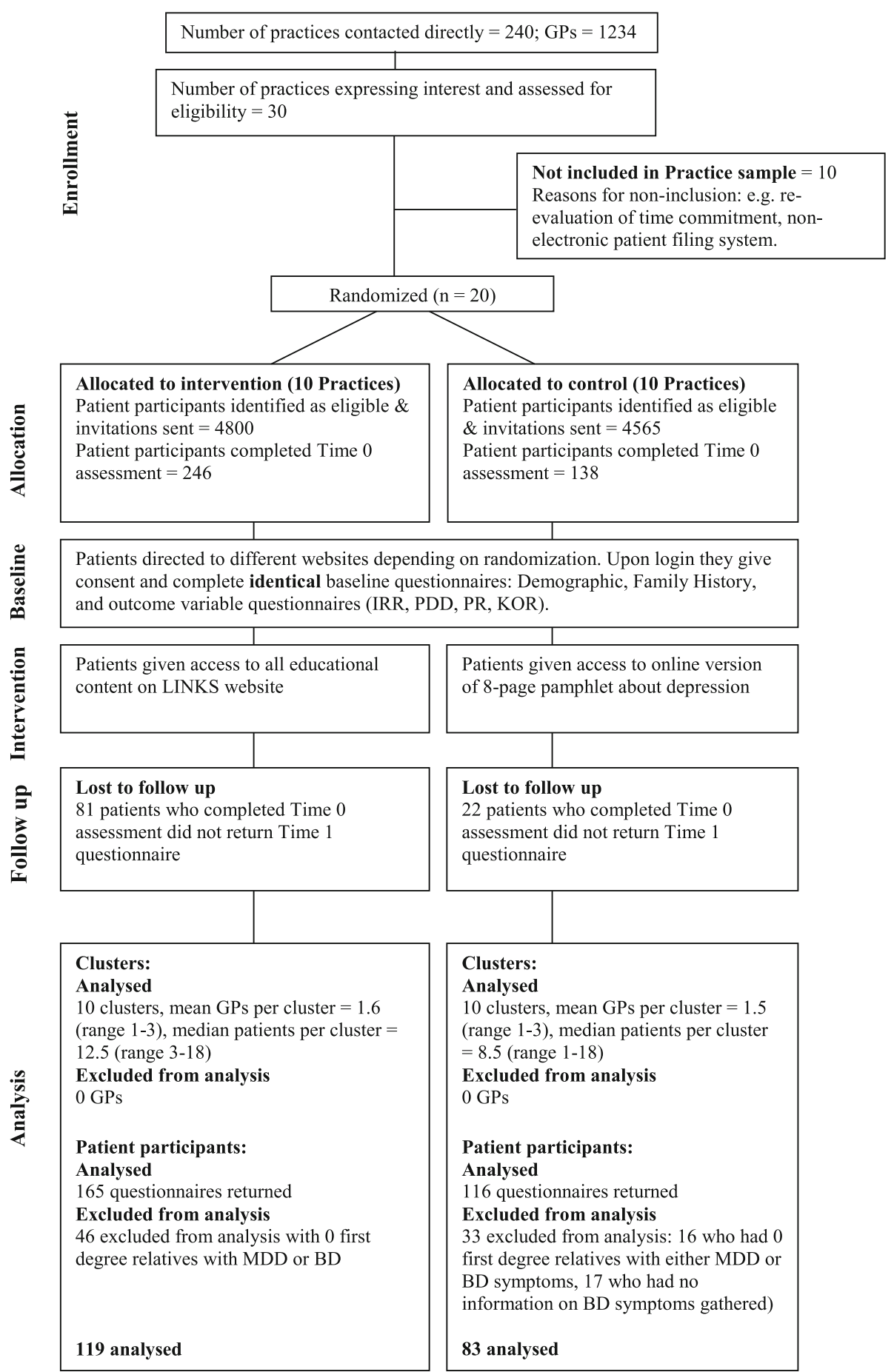

Fig. 1 Diagram showing the flow of clusters and participants throughout the study

diet, minimising alcohol and street-drug use, good social support, optimism/having a positive attitude, and religiosity/spirituality). The information was conveyed via 50 screens and eight embedded videos, with an emphasis on visual illustrations of key concepts over text, e.g. 'The mental illness jar model' developed by Peay and Austin
[40]. Where text was used, it was at a ninth-grade reading level. A risk assessment tool was also included in the website. Upon completing a family history of MDD and bipolar disorder questionnaire, the Family History Screen (FHS) [41], the user received a visualised estimate of lifetime risks and risks over the next year of 
developing MDD or BD relative to the general population. In total 12 different risk scenarios could be visualised. The features of the website are described in more detail in a previous paper [42].

\section{Control condition}

The control condition was a link to an online version of a leaflet on depression produced by beyondblue (the Australian national depression initiative), which briefly described depressive symptoms, strategies for reducing depression, and where to seek treatment.

\section{Questionnaires}

Participants completed two measures at baseline only (the FHS and items eliciting socio-demographic variables) and an additional five measures at both baseline and 2-week follow-up. These measures are described in Table 1.

\section{Procedures}

Each practice was randomised once signed consent was obtained from the participating GPs. The 20 participating practices were randomly assigned based on anonymous practice ID numbers to either the intervention or control condition according to a $2 \times 10$ block design generated by an online randomisation tool (https://www.random.org/). Following randomisation, practice managers were instructed by researchers on how to implement the study. Researchers worked with staff at GP practices to generate random lists of up to 500 patients per practice. GPs were asked to scan these lists and exclude those patients who would not be suitable (e.g. cognitive impairment, severe illness, patients with a psychiatric disorder that was currently not well controlled). Those deemed suitable were sent a letter of invitation by their GP. Potential participants were blinded to their intervention assignment by being told in the invitation letter that the purpose of the study was to compare two types of educational interventions. The letter invited those who self-identified as having at least one FDR who had an episode of depression at some point in their life to enter the LINKS study. The letter contained a link to either the LINKS website or to the control website depending on participants' GP practice

Table 1 Description of measures and time points administered

\begin{tabular}{|c|c|c|c|}
\hline Measure & Description of Measure & Baseline $^{*}$ & 2-week follow-up \\
\hline Socio-demographic Questionnaire & $\begin{array}{l}\text { Measures sex, age, education level, employment status, marital } \\
\text { status, country of birth and language spoken at home. }\end{array}$ & $\checkmark$ & \\
\hline Family History Screen (FHS) [41] & $\begin{array}{l}\text { Screens lifetime history of MDD and BD symptoms of the participant } \\
\text { and of all first-degree relatives. Lifetime history is based on } \\
\text { self-assessment rather than by clinician diagnosis. }\end{array}$ & $\checkmark$ & \\
\hline $\begin{array}{l}\text { Intention to adopt, and adoption } \\
\text { of, risk reducing strategies (IRR) }\end{array}$ & $\begin{array}{l}\text { 8-item scale measuring whether participants intended to or had } \\
\text { already: (i) undergone psychological therapy, (ii) been taking regular, } \\
\text { moderate-intensity exercise, (iii) been sleeping } 7-9 \text { hours per day, } \\
\text { (iv) started a low-fat, 'Mediterranean' diet, (v) been taking vitamin D, } \\
\text { (vi) been ensuring they had sufficient social support, (vii) been trying } \\
\text { to adopt optimistic or positive mental attitude, (viii) been } \\
\text { developing their spirituality. 5-point response option: 0-Do not } \\
\text { intend to in the next } 6 \text { months; } 1-N o \text {, but intend to in the next } \\
\text { six months; } 2-N o, \text { but intend to in the next } 30 \text { days; } 3 \text {-Have already } \\
\text { for }<6 \text { months; } 4 \text {-have for }>6 \text { months". The } 5 \text { items were collapsed } \\
\text { into a single dichotomous variable: }(0) \text {-no intention to adopt the } \\
\text { risk-reducing strategy vs }(1,2,3,4)-\text { intend to or have already adopted } \\
\text { the risk-reducing strategy. }\end{array}$ & $\checkmark$ & $\checkmark$ \\
\hline $\begin{array}{l}\text { Patient Health Questionnaire } \\
\text { (PHQ9) [54] }\end{array}$ & $\begin{array}{l}\text { 10-item self-report scale assessing symptoms based on DSM-IV } \\
\text { criteria for MDD. 4-point response scale. Max. score }=30 . \\
\text { Higher score }=\text { more depressive symptoms. }\end{array}$ & $\checkmark$ & $\checkmark$ \\
\hline $\begin{array}{l}\text { Perceived Devaluation-Discrimination } \\
\text { Questionnaire (PDD) [55] }\end{array}$ & $\begin{array}{l}\text { 12-item scale measuring perceived social stigma surrounding mental } \\
\text { illness. } 4 \text {-point response scale. Max. score } 48 \text {. Higher score = more } \\
\text { perceived stigma. }\end{array}$ & $\checkmark$ & $\checkmark$ \\
\hline $\begin{array}{l}\text { Knowledge of Risk Factors and } \\
\text { Risk-Reduction Strategies for } \\
\text { Depression (KOR) }\end{array}$ & $\begin{array}{l}\text { 10-item veridical test, developed for this study, designed to assess } \\
\text { knowledge of proven risk factors for developing depression } \\
\text { and strategies to reduce risk of developing depression. True/False } \\
\text { answer. Max. score }=10 \text {. Higher score = more accurate knowledge. }\end{array}$ & $\checkmark$ & $\checkmark$ \\
\hline $\begin{array}{l}\text { Perceived Risk of Developing } \\
\text { Depression and Bipolar Disorder (PR) [56] }\end{array}$ & $\begin{array}{l}\text { 4-item scale adapted from a previous study [56]. Two items each } \\
\text { pertaining to MDD and BD. The first of these two items measures } \\
\text { perceived relative risk of developing the disorder sometime in } \\
\text { the future compared to others of the same age and gender } \\
\text { (5-point scale; Max. score = 5, higher score = higher perceived risk). } \\
\text { In second of two items respondent indicate their perceived \% } \\
\text { chance of developing the disorder sometime in the future } \\
\text { (0-100 VA scale; Max. score = 100; higher score = higher perceived risk) }\end{array}$ & $\checkmark$ & $\checkmark$ \\
\hline
\end{tabular}


allocation. Upon following the provided link, participants were asked to give consent. They were then asked to complete the baseline survey, containing the socio-demographic items, FHS, and outcome measures. After completing the baseline survey, participants were given free access to the website material and were asked to complete the follow up survey within 14 days. Reminders were sent as required.

\section{Statistical analyses}

In order to estimate changes in outcome variables over time while taking account of clustering, random-intercepts hierarchical linear regression models were fitted for each outcome variable, with the second measurement occasion (2-week follow-up) as the outcome variable, intervention group as the primary predictor, baseline score for the same outcome variable as covariate, and practice ID as the random factor. For dichotomous variables, relative odds were estimated using hierarchical logistic regression. Differences between the intervention and control arms in changes in quantitative outcomes were estimated using normal hierarchical linear regression. Intra-cluster correlation coefficients (ICCs) were calculated for all variables. Where the estimated ICC from the hierarchical model was negative for any analysis, it was assumed to be 0 , as true negative ICCs are rare in this context. Baseline differences in gender, age, and family history of MDD or BD were examined for possible inclusion as covariates in regression models (discussed in 'Results' below). Analyses were performed using the lme4 [43], ICC [44] and base packages in R [45].

\section{Technical limitations and their impact}

Due to a technical error with the automated screening procedure on the LINKS website, 79 participants who proceeded through the trial had no FDRs with a history of MDD or BD. These participants were excluded from analyses. A further technical error resulted in the questions relating to symptoms of $\mathrm{BD}$ not being present in the FSH questionnaire for the first 22 participants who used the control group's website; thus these participants could not be included in analysis. In addition, as a result of a technical error involving the website used to administer the follow-up questionnaires, only one of the eight strategies for reducing risk of depression contained in the baseline questionnaire had matching data collected in the follow-up questionnaire: intention to undergo or currently undergoing psychological therapy as a preventative strategy. While this error was regrettable, this risk reduction strategy has the most evidence for efficacy at preventing depression [17, 21-24]. Finally, while the study protocol had included a six-month follow-up [46], financial and time constraints meant this could not be completed.

\section{Results}

Of the 30 practices that expressed an interest in taking part in the trial, ten did not take part, either because they subsequently decided they could not devote sufficient resources to conducting the trial, or because they had paper-based filing systems that were unsuitable for generating patient lists. This left 20 practices (clusters) to take part in the trial (Fig. 1).

The median number of participants per practice whose results were analysed was 11 . Although the practices invited to participate were selected to be as culturally and socioencomically diverse as possible, of the practices who agreed to take part in the study $12 / 20$ practices were located in suburbs in the top quartile of rankings of the 2011 Socioeconomic Index For Areas (SEIFA) [47], $7 / 20$ in the third quartile, and $1 / 20$ in the second quartile (Table 1). As such SEIFA percentile rank was included in all analyses as a level-2 covariate.

Three hunderd and 84 individuals completed the baseline questionnaire and, of these, 281 also completed the two-week follow-up questionnaire. Excluded from analysis were 62 participants who indicated in the FHS questionnaire that they had no FDRs with a history of MDD or BD symptoms and 17 who did not have information about FDRs with BD symptoms collected, leaving 202 participants in total $($ control $=83$, intervention $=119)$ included in analyses.

Baseline characteristics at the cluster and individual level are shown in Tables 2 and 3. Of the demographic variables, only family history with symptoms of MDD or BD showed any imbalance between intervention and control at baseline, with $33.6 \%$ of participants in the intervention group having at least one FDR with bipolar symptoms, compared to 20.5 in the control group. Consequently family history with $\mathrm{BD}$ was included as a level-1 covariate in analyses.

\section{Intention to adopt, and adoption of, risk reducing strategies}

The increase in the proportion of individuals who intended to undergo or had undergone psychological therapy from baseline to 2-week follow-up was $22.1 \%$, in the intervention group, compared to $0.0 \%$ increase in the control group (Table 4). This meant that, after adjusting for baseline, the estimated odds of intending to undergo therapy or currently undergoing therapy were 5.83 times higher in the intervention group (95\% CI: 1.58-21.47, $p=.008$ ).

\section{Knowledge of risk factors and risk reduction strategies for depression}

The estimated increase in knowledge of depression risk factors was 0.47 points greater in the intervention group than in the control group (95\% CI: $0.05-0.88, p=.029$ ). 
Table 2 Baseline information for each trial arm at the practice (cluster) level

\begin{tabular}{|c|c|c|c|c|}
\hline Variables & & $\begin{array}{l}\text { Intervention group } \\
(N=10) \\
\text { Mean (SD) }\end{array}$ & $\begin{array}{l}\text { Control group }(N=10) \\
\text { Mean }(S D)\end{array}$ & $\begin{array}{l}\text { Total sample } \\
(N=20) \\
\text { Mean (SD) }\end{array}$ \\
\hline Mean no. of participating GPs per practice/cluster & Range: 1,3 & $1.6(0.8)$ & $1.5(0.7)$ & $1.55(0.8)$ \\
\hline \multirow{2}{*}{$\begin{array}{l}\text { Mean no. of GPs per practice/cluster (participating } \\
\text { and non-participating) }\end{array}$} & Range 1, 20 & $7.9(4.6)$ & $9.7(7.2)$ & $8.8(5.9)$ \\
\hline & Level & $N(\%)$ & $N(\%)$ & $N(\%)$ \\
\hline \multirow[t]{2}{*}{ Full-time practice manager } & Yes & $6(60)$ & $7(70)$ & $13(65)$ \\
\hline & No & $4(40)$ & $3(30)$ & $7(35)$ \\
\hline \multirow[t]{2}{*}{ Billing arrangements ${ }^{a}$} & Bulk-billing all patients & $2(20)$ & $5(50)$ & $7(35)$ \\
\hline & Private Billing & $8(80)$ & $5(50)$ & $13(65)$ \\
\hline \multirow[t]{5}{*}{ SES of Practice Location ${ }^{b}$} & Rank (in Quartiles) & & & \\
\hline & $75-100$ & $6(60)$ & $6(60)$ & $12(60)$ \\
\hline & $50-75$ & $3(40)$ & $4(40)$ & $7(35)$ \\
\hline & $25-50$ & $1(0)$ & $0(0)$ & $1(5)$ \\
\hline & $1-25$ & $0(0)$ & $0(0)$ & $0(0)$ \\
\hline
\end{tabular}

${ }^{a}$ Bulk-billing all patients refers to practices where the cost of the visit for all patients is covered by Medicare, Australia's universal health care plan. Private billing in this case refers to practices that had either only private billing (i.e. visit paid for upfront or by a private health care fund) or a combination of private billing and bulk-billing

${ }^{b}$ Based on Percentile Ranks within NSW contained in the 2011 Socioeconomic Index for Areas (SEIFA) published by the Australian Bureau of Statistics. Higher ranks indicate higher socioeconomic status

\section{Perceived risk of developing bipolar disorder}

Being allocated to the intervention group also resulted in $11.3 \%$ greater accuracy in estimating risk of developing $\mathrm{BD}$ compared to the control group (95\% CI: $-16.52--5.73$, $p<.001)$. That is, intervention group participants were less likely to overestimate lifetime risk for BD (26.67\%) compared to control participants $(35.50 \%)$. The correct lifetime risk for BD was $10 \%$. Perceived lifetime risk for MDD was not significantly different between the intervention group (43.07\%) and the control group participants (49.16\%), with the correct lifetime risk being $25 \%$. There were no statistically significant between-group differences in change from baseline to follow-up for any of the remaining outcome variables (Patient Health Questionnaire, Perceived Devaluation-Discrimination Questionnaire and Perceived Risk of Developing MDD).

\section{Discussion}

This cluster randomised controlled trial tested a novel interactive online psychoeducational intervention developed specifically for individuals with a family history of MDD and/or BD. The results show that the LINKS website increased users' intention to adopt or actual adoption of psychological therapy as a preventative measure against depression. Psychological therapy is the depression prevention strategy that has by far the most evidence for its efficacy, thus it is encouraging that exposure to the LINKS website was associated with an increase in users' willingness to seek therapy in order to reduce their future risk of developing depression. The website also increased participants' knowledge of both the risk factors for developing depression and strategies for reducing depression. Psychoeducational interventions have been shown to be associated with compliance with medication [48] and willingness to seek help for depression [49]. Though it was not tested statistically in this study, it seems likely that the increase in knowledge of risk factors and prevention strategies could have been the cause of the observed increase in willingness to seek therapy. Future studies may wish to test the relationship more formally via structural equation modelling.

Importantly, the LINKS website also improved participants' accuracy at estimating the future risk of developing bipolar disorder. Many with a family history of MDD and/ or BD greatly overestimate the risk of passing this condition to their children $[2,50]$ and can be reluctant to start a family as a result [35]. A resource that allows those at familial risk of MDD or $\mathrm{BD}$ to develop more realistic estimates of future risk of BD to their children could be very valuable in helping allay the fears of these individuals and assist them in making more informed reproductive decisions. The reduction of overestimation of risk for $\mathrm{BD}$ may also lead to decreased self-stigmatisation. Research demonstrated that stigma is experienced and internalised by family members of people with mental illness, causing adverse outcomes including psychological distress and decreased quality of life [51], which may be mitigated by more accurate risk estimation for BD. By contrast, the LINKS website failed to reduce the percentage of participants overestimating their risk of MDD; one might speculate that risks for $\mathrm{BD}$ may be better retained because of a perception that $\mathrm{BD}$ is a more serious disorder than MDD. 
Table 3 Demographic and family history variables at the patient (individual) level

\begin{tabular}{|c|c|c|c|c|}
\hline Variables & & $\begin{array}{l}\text { Intervention group }(N=119) \\
\text { Mean }(\mathrm{SD})\end{array}$ & $\begin{array}{l}\text { Control group }(N=83) \\
\text { Mean (SD) }\end{array}$ & $\begin{array}{l}\text { Total sample } \\
(N=202) \\
\text { Mean (SD) }\end{array}$ \\
\hline \multirow[t]{2}{*}{ Age } & Range: 18, 74 & $44.0(14.7)$ & $40.2(12.4)$ & $42.42(13.9)$ \\
\hline & Level & $N(\%)$ & $N(\%)$ & $N(\%)$ \\
\hline \multirow[t]{2}{*}{ Gender } & Male & $25(21.0)$ & $14(16.9)$ & $39(19.3)$ \\
\hline & Female & $94(79.0)$ & $69(83.1)$ & $163(80.7)$ \\
\hline \multirow[t]{5}{*}{ Highest education level achieved } & Other & $2(1.7)$ & $2(2.4)$ & $4(2.0)$ \\
\hline & Some High School & $15(12.6)$ & $9(3.6)$ & $24(11.9)$ \\
\hline & Graduated High School & $8(6.7)$ & $3(10.9)$ & $11(5.4)$ \\
\hline & Vocational college & $33(27.7)$ & $24(28.9)$ & $57(28.2)$ \\
\hline & Degree/Postgraduate degree & $61(51.3)$ & $45(54.2)$ & $106(52.5)$ \\
\hline \multirow[t]{4}{*}{ Occupation } & Wages/Salary/Self-Employed & $79(66.4)$ & $54(65.1)$ & $133(65.8)$ \\
\hline & Student & $10(8.4)$ & $9(10.8)$ & $19(9.4)$ \\
\hline & Retired/Unemployed & $20(16.8)$ & $8(9.6)$ & $28(13.9)$ \\
\hline & Other & $10(8.4)$ & $12(14.5)$ & $22(10.9)$ \\
\hline \multirow[t]{2}{*}{ Marital status } & Married/living as married & $50(42.0)$ & $33(39.8)$ & $83(41.1)$ \\
\hline & Never married/Divorced/Widowed & $69(58.0)$ & $50(60.2)$ & $119(58.9)$ \\
\hline \multirow[t]{2}{*}{ Children } & Yes & $73(61.3)$ & $43(51.8)$ & $116(57.4)$ \\
\hline & No & $46(38.7)$ & $40(48.2)$ & $86(42.6)$ \\
\hline \multirow[t]{2}{*}{ Country of Birth } & Australia & $96(80.7)$ & $56(67.5)$ & $152(75.3)$ \\
\hline & Other & $23(19.3)$ & $27(32.5)$ & $50(24.7)$ \\
\hline \multirow[t]{2}{*}{ Language spoken mostly at home } & English & $119(100.0)$ & 79 (95.2) & $198(98.0)$ \\
\hline & Language other than English & $0(0.0)$ & $4(4.8)$ & $4(2.0)$ \\
\hline \multirow[t]{2}{*}{ Personal symptoms of MDD or $\mathrm{BD}^{\mathrm{a}}$} & MDD Symptoms Only & $60(50.4)$ & $47(56.6)$ & $107(53.0)$ \\
\hline & BD Symptoms ${ }^{c}$ & $14(11.8)$ & $8(9.6)$ & $22(10.9)$ \\
\hline \multirow[t]{6}{*}{ Symptoms of first-Degree relatives ${ }^{b}$} & 1 FDR with MDD Symptoms Only & $55(46.2)$ & $35(42.2)$ & $90(44.6)$ \\
\hline & 2 FDR with MDD Symptoms Only & $19(16.0)$ & $24(28.9)$ & $43(21.3)$ \\
\hline & 3 FDR with MDD Symptoms Only & $3(2.5)$ & $7(8.4)$ & $10(5.0)$ \\
\hline & $>3$ FDR with MDD Symptoms Only & $2(1.7)$ & $0(0.0)$ & $2(1.0)$ \\
\hline & 1 FDR with BD Symptoms ${ }^{c}$ & $33(27.7)$ & $15(18.1)$ & $48(23.8)$ \\
\hline & 2 FDR with BD Symptoms ${ }^{c}$ & $7(5.9)$ & $2(2.4)$ & $9(4.5)$ \\
\hline
\end{tabular}

${ }^{\mathrm{a}}$ As assessed by the Family History Screen

${ }^{\mathrm{b}}$ Total number in this analysis was 202 after excluding participants in the control group whose questionnaires were incomplete. Entry refers to type of history (MDD only versus $\mathrm{BD}$ ) in first-degree relatives

${ }^{\mathrm{c}}$ Either with or without presence of MDD symptoms

The intervention did not produce a significant reduction in self-reported depressive symptoms or perceived stigma surrounding MDD and BD. While psychoeducational websites have been found to be as effective at reducing depressive symptoms as websites that deliver cognitive behavioural therapy [16], there are indications that, even for online cognitive behavioural therapy, a longer time frame is generally required to observe significant improvement in symptoms [52]. Psychoeducational interventions have also proven effective at reducing stigma surrounding mental illness [53], and there is evidence that having a genetic explanation for depression can reduce the perceived stigma surrounding the condition [35]. Given that there was only 2 weeks between baseline and follow-up measures in this study, a significant change in depressive symptoms and perceived stigma was perhaps unlikely.

\section{Study limitations}

The technical difficulties in the study were disappointing. Chief among these was the omission of questions concerning participants' intentions to engage in the seven other strategies for reducing depression from the follow-up questionnaire. Fortunately, we did obtain data 
Table 4 Results of outcome variables

\begin{tabular}{|c|c|c|c|c|c|c|c|c|c|c|}
\hline \multirow[t]{2}{*}{ Variables } & \multicolumn{3}{|c|}{ Intervention group } & \multicolumn{4}{|c|}{ Control group } & \multicolumn{3}{|l|}{ Adjusted } \\
\hline & $\mathrm{N}$ & Baseline & Follow-Up & $\mathrm{N}$ & Baseline & Follow-Up & ICC & $\begin{array}{l}\text { Comparative } \\
\text { statistic }^{\mathrm{a}}\end{array}$ & 95\% Cl statistic & $p$ \\
\hline $\begin{array}{l}\text { Intention to Undergo Therapy } \\
\text { as a Risk Reduction Strategy }\end{array}$ & 113 & $0.47(.50)$ & $0.69(.46)$ & 83 & $0.75(.44)$ & $0.75(.44)$ & $0^{b}$ & 5.83 & $1.58-21.47$ & 0.008 \\
\hline Patient Health Questionnaire & 119 & $6.49(6.0)$ & $5.48(5.5)$ & 81 & $7.56(6.3)$ & $6.64(5.3)$ & 0.068 & 0.25 & $-0.74-1.24$ & 0.625 \\
\hline $\begin{array}{l}\text { Perceived Devaluation } \\
\text { and Discrimination }\end{array}$ & 117 & $20.62(4.8)$ & $19.74(5.1)$ & 83 & $20.57(5.4)$ & $19.61(5.8)$ & 0.044 & 0.29 & $-0.98-1.56$ & 0.662 \\
\hline Knowledge of Risk Factors & 117 & $6.08(1.8)$ & $7.16(1.6)$ & 83 & $6.08(1.8)$ & $6.74(1.5)$ & $0^{\mathrm{b}}$ & 0.47 & $0.05-0.88$ & 0.029 \\
\hline \multicolumn{11}{|l|}{ Perceived Risk } \\
\hline \multicolumn{11}{|l|}{ MDD } \\
\hline Comparative Risk & 114 & $2.47(1.0)$ & $2.34(1.1)$ & 83 & $2.54(1.2)$ & $2.40(1.1)$ & $0^{b}$ & -0.03 & $-0.27-0.20$ & 0.774 \\
\hline$\%$ Risk & 114 & $46.93(24.6)$ & $43.07(26.4)$ & 83 & $51.69(30.6)$ & $49.16(30.1)$ & 0.026 & -2.66 & $-7.87-2.55$ & 0.319 \\
\hline \multicolumn{11}{|l|}{$\mathrm{BD}$} \\
\hline Comparative Risk & 113 & $1.54(1.0)$ & $1.51(1.0)$ & 83 & $1.43(1.3)$ & $1.63(1.3)$ & 0.054 & -0.21 & $-0.51-0.09$ & 0.195 \\
\hline$\%$ Risk & 114 & $35.44(22.5)$ & $26.67(18.8)$ & 92 & $32.77(28.2)$ & $35.30(28.6)$ & 0.002 & -11.13 & $-16.52--5.73$ & $<0.001$ \\
\hline
\end{tabular}

Significant findings in bold

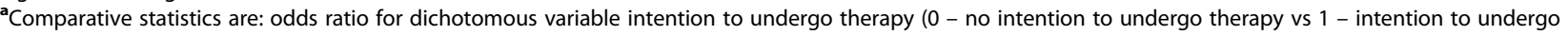
therapy or actually have undergone therapy) and estimated mean difference for all remaining continuous variables

${ }^{\mathrm{b}}$ If ICC $<0$ it was assumed to be equal to 0 . All analyses used randomisation as the primary predictor and: (1) family history with MDD and BD symptoms, and (2) SES of GP practice location, as covariates

on change in willingness to adopt the preventative factor with by far the most evidence, however the missing questions pertained to lifestyle factors that do not have the potential stigma of psychological therapy and which participants may have been thus more willing to adopt. The other main limitation was the lack of a longer-term follow-up. Health education delivery systems typically take longer periods of time to result in significant behavioural change. It would be interesting to see whether exposure to the website resulted in actual change in uptake of risk reduction strategies, and whether other variables such as depression symptoms or perceived stigma were affected over a longer time frame. Another limitation worth mentioning is that web analytic data was not collected on how many times or for how long each participant visited the LINKS website during the 2 -week study period. Inclusion in the analysis of number of site visits and/or duration of the average visit as level-1 covariates may have provided a more detailed picture of the relationship between exposure to the site and the outcome variables. Another limitation is that only $19 \%$ of participants were male and hence generalisability of the findings to men may be limited. Self-assessment of diagnosis of MDD or BD in participants' FDRs is also a limitation. Final limitations relate to the lack of data on the impact of family history, about the care received and the frequency of GPs' reports on family history.

\section{Practical implications}

The results of this study highlight the promise of targeted online psychoeducational interventions for delivery of information relevant to those at familial risk of psychiatric conditions. The fact that the website resulted in improved knowledge of risk factors, prevention strategies, and accuracy of estimated future risk should encourage health care providers to invest in the development of similar online psychoeducational resources for other psychiatric conditions. The website is also available for translation into other languages. Although the website was tested on patients in the primary health care setting, it would also be suitable for patients concerned about their familial risk of depression who are seen by psychiatrists, psychologists, genetic counsellors and clinical geneticists. LINKS and similar interactive educational websites should be recommended by health professionals for those who are concerned about their familial risk of developing other psychiatric disorders and medical conditions. Another application of the website in the healthcare system might be to screen individuals for early signs and symptoms to target it to subsyndromal individuals as the most likely group to benefit from the education on prevention strategies.

\section{Research recommendations}

Results from this study demonstrate that an interactive, online psychoeducational website can increase both knowledge of strategies to prevent depression and willingness to adopt therapy as a depression prevention strategy in people with a familial risk. It would be worthwhile testing whether the LINKS website or similar websites also result in willingness to adopt other lifestyle (e.g. exercise, sleep, diet) or psychosocial (e.g. optimism, social support, or spirituality) prevention strategies in a 
similar way. In order to test whether the increase in knowledge of, and intention to adopt, risk reduction strategies observed over the 2-week study period translates to actual adoption of those strategies, future studies should examine change over a longer time frame (e.g. 6 months or 1 year). A longer time frame might also allow for manifestation of observable changes in actual depression symptoms or in perceived stigma. It would also be of interest to survey GPs regarding the intervention and assess its impact on patients' help-seeking behaviours. Finally, future large-scale prospective studies should also assess whether the impact of providing information about early warning as part of the intervention may lead to earlier detection and treatment.

\section{Abbreviations \\ BD: Bipolar disorder; FDR: First-degree relative; MDD: Major depressive disorder}

\section{Acknowledgements}

We are very grateful to all the GPs and patients for their assistance and participation in this study.

\section{Funding}

This study was funded by the Australian Research Council (ARC) Linkage Grant LP120200075 to BM, PJM, PRS, KB-S, LT, TD and HC. The funding body played no role in the design of the study and collection, analysis, and interpretation of data and in writing the manuscript.BM was supported by Senior Research Fellowship (ID 1078523) from the Australian National Health and Medical Research Council (NHMRC), and PJM and PRS were also supported by NHMRC Program Grant 1037196. Michelle Peate was supported by an Early Career Fellowship (ECF-015) from the National Breast Cancer Foundation.

\section{Availability of data and materials}

The dataset used and/or analysed in the present study are available from the corresponding author at request.

\section{Authors' contributions}

BM led the design and conduct of this work. LM and BM were responsible for data integrity and analyses for the study. BM, PRS, MP, LT, KBS, TD, HC, KS, $K D$ and PBM contributed to the study concept and design. BM, PRS, LT, KBS, $T D, H C$ and PBM were involved in the acquisition of funding. BM, RA, MP, and $C L$ were responsible for data acquisition. $L M$ was responsible for the statistical analyses and interpretation. LM drafted the manuscript, and BM revised it to incorporate all authors' revisions and suggestions made by the reviewers. All authors contributed to the critical revision of the manuscript for intellectual content. BM is guarantor. All authors read and approved the final manuscript.

\section{Ethics approval and consent to participate}

The study received ethics approval from the institutional review board of the University of New South Wales, Sydney (HREC Ref: \# HC13368) and participants provided informed consent online before taking part in the study.

\section{Consent for publication}

Not applicable.

\section{Competing interests}

Bettina Meiser has a remunerated consultant role with the company Astrazeneca with respect to an unrelated project.

\section{Publisher's Note}

Springer Nature remains neutral with regard to jurisdictional claims in published maps and institutional affiliations.

\section{Author details}

${ }^{1}$ Psychosocial Research Group, Prince of Wales Clinical School, UNSW, Sydney, Australia. ${ }^{2}$ Neuroscience Research Australia, Sydney, Australia. ${ }^{3}$ School of Medical Sciences, UNSW, Sydney, Australia. ${ }^{4}$ Department of Obstetrics and Oncology, Royal Women's Hospital, University of Melbourne, Melbourne, VIC 3052, Australia. ${ }^{5}$ School of Psychiatry, UNSW, Sydney, Australia. ${ }^{6}$ School of Public Health, University of Sydney, Sydney, Australia. ${ }^{7}$ Sydney Medical School - Northern, University of Sydney, Sydney, Australia. ${ }^{8}$ National Drug and Alcohol Research Centre, UNSW Sydney, Sydney, Australia. ${ }^{9}$ Black Dog Institute, Sydney, Australia. ${ }^{10}$ Centre for Emotional Health, Department of Psychology, Macquarie University, Sydney, Australia.

${ }^{11}$ Centre for Genetics Education NSW Health, Sydney, Australia.

Received: 14 December 2017 Accepted: 19 December 2018

Published online: 17 January 2019

\section{References}

1. Sullivan P, Neale M, Kendler K. Genetic epidemiology of major depression: review and meta-analysis. Am J Psychiatr. 2000;157:1552-62.

2. Merikangas K, Chakravarti A, Moldin S, Araj H, Blangero J, Burmeister M, et al. Future of genetics in mood research. Biol Psychiatry. 2002;52(6):457-77.

3. Kendler K, Prescott C. A population-based twin study of lifetime major depression in men and women. Arch Gen Psychiatry. 1999;56(1):39-44.

4. Kieseppa T, Partonen T, Haukka J, Kaprio J, Lönnqvist J. High concordance of bipolar I disorder in a nationwide sample of twins. Am J Psychiatr. 2004; 161:1814-21.

5. McGuffin P, Rijsdijk F, Andrew M, Sham P, Katz R, Cardno A. The heritability of bipolar disorder and the genetic relationship to unipolar despression. Arch Gen Psychiatry. 2003;60:497-502.

6. Wilde A, Chan H, Rahman B, Meiser B, Mitchell B, Schofield P, Green M. A meta-analysis of the risk of major affective disorder in relatives of individuals affected by major depressive disorder or bipolar disorder. J Affect Disord. 2014;158:37-47.

7. Austin J, Smith G, Honer W. The genomic ear and perceptions of psychotic disorders: genetic risk estimation, associations with reproductive decisions and views about predictive testing. Am J Med Genet B. 2006;141B:926-8.

8. Quinn V, Wilde A, Meiser B, Cousins Z, Barlow-Stewart K, Mitchell P, Schofield P. Preferences regarding targeted education and risk assessment in people with a family history of major depressive disorder. J Genet Counsel. 2014;23:785-95.

9. Peay H, Hooker G, Kassem L, Biesecker B. Family risk and related education and counseling needs: perceptions of adults with bipolar disorder and siblings of adults with bipolar disorder. Am J Med Genet A. 2009;149A(3):364-71.

10. Inglis A, Koehn D, McGillivray B, Stewart S, Austin J. Evaluating a unique, specialist psychiatric genetic counseling clinic: uptake and impact. Clin Genet. 2015;87(3):218-24.

11. Hippman C, Ringrose A, Inglis A, Cheek J, Albert A, Remick R, Honer W, Austin J. A pilot randomised clinical trial evaluating the impact of genetic counseling for serious mental illnesses. J Clin Psychiatry. 2016;77(2):190-8.

12. Costain G, Esplen M, Toner B, Hodgkinson K, Bassett A. Evaluating genetic counseling for family members of individuals with schizophrenia in the molecular age. Schizophr Bull. 2014;40(1):88-99.

13. Christensen H, Griffiths KM, Korten A. Web-based cognitive behavior therapy: analysis of site usage and changes in depression and anxiety scores. J Med Internet Res. 2002;4(1).

14. Donker T, Griffiths K, Cuijper P, Christensen H. Psychoeducation for depression, anxiety and psychological distress: a meta-analysis. BMC Med. 2009;2009(7):79

15. Jorm AF, Barney $L$, Christensen $H$, Highet NJ, Kelly CM, Kitchener BA. Research on mental health literacy: what we know and what we still need to know. Aust N Z J Psychiatry. 2006;40(1):3-5.

16. Mackinnon A, Griffiths K, Christensen H. Comparative randomised trial of online cognitive-behavioural therapy and an information website for depression: 12-month outcomes. Br J Psychiatry. 2008;192:130-4.

17. Barrera A, Torres L, Munoz R. Prevention of depression: the state of the science at the beginning of the 21st century. Int Rev Psychiatry. 2007; 19(6):655-70.

18. Cuijpers P, Beekman A, Reynolds C. Preventing depression: a global priority. JAMA. 2012;307(10):1033-4. 
19. Beardslee W, Brent D, Weersing V, Clarke G, Porta G, Hollon S, et al. Prevention of depression in at-risk adolescents: longer-term effects. JAMA Psychiatry. 2013;70(11):1161-70.

20. Cuijpers P, Donker T, Johansson R, Mohr D, van Straten A, et al. Self-guided psychological treatment for depressive symptoms: a meta-analysis. PLoS One. 2011;6(6):e21274

21. Cuijpers P, van Straten A, Smit F, Mihalopoulos C, Beekman A. Preventing the onset of depressive disorders: a meta-analytic review of psychological interventions. Am J Psychiatr. 2008;165:1272-80.

22. Merry S, McDowell H, Hetrick S, Bir J, Muler N. Psychological and/or educational interventions for the prevention of depression in children and adolescents. Cochrane Database Syst Rev. 2004;(1):CD003380

23. Clarke $G$, Hornbrook M, Lynch F, et al. A randomised trial of a group cognitive intervention for depression in adolsecent offspring of depressed patients. Arch Gen Psychiatry. 2001;58(12):1127-34.

24. Garber J, Clarke G, Weersing R. Prevention of depression in at-risk adolescents: a randomised controlled trial. JAMA. 2009:301(21):2215-24

25. Larun L, Nordheim L, Ekeland E, Hagen K, Heian F. Exercise in prevention and treatment of anxiety and depression among children and young people. Cochrane Database Syst Rev. 2006;3.

26. Davis L, Uezato A, Newell J, Frazier E. Major depression and comorbid substance use disorders. Curr Opin Psychiatr. 2008;21:14-8.

27. Perlman C, Johnson S, Mellmand T. The prospective impact of sleep duration on depression and mania. Bipol Dis. 2006;8(3):271-4.

28. Skarupski K, Tangney C, Li H, Evans D, Morris M. Mediterranean diet and depressive symptoms over time. J Nutr Health Aging. 2013;17(5):441-5.

29. Berk M, Sanders K, Pasco J, Jacka F, Williams L, Hayles A, Dodd S. Vitamin D deficiency may play a role in depression. Med Hypotheses. 2007;69(6):1316-9.

30. Stice E, Ragan J, Randall P. Prospective relations between social support and depression: differential direction of effects for parent and peer support? J Abnorm Psychol. 2004;113(1):155-9.

31. Seligman M, Steen T, Park N, Peterson C. Positive psychology Progress: empirical validation of interventions. Am Psychol. 2005;60(5):410-21.

32. Jacobs M, Miller L, Wickramaratne P, Gameroff M, Weissman M. Family religion and psychopathology in children of depressed mothers: ten-year follow-up. J Affect Disord. 2012;136:320-7.

33. Kasen S, Wickramaratne P, Gameroff M, Weissman M. Religiosity and resilience in persons at high risk for major depression. Psychol Med. 2012;42:509-19.

34. Griffiths KM, Christensen H, Jorm AF, Evans K, Groves C. Effect of web-based depression literacy and cognitive-behavioural therapy interventions on stigmatising attitudes to depression. Br J Psychiatry. 2004;185(4):342-9.

35. Meiser B, Mitchell PB, Kasparian NA, Strong K, Simpson JM, Mireskandari S, Tabassum L, Schofield PR. Attitudes towards childbearing, causal attributions for bipolar disorder and psychological distress: a study of families with multiple cases of bipolar disorder. Psychol Med. 2007;37(11):1601-11.

36. Ansseau M, Dierick M, Buntinkx F, Cnockaert P, De Smedte J, Van Den Haute M, Vander Mijnsbrugge D. High prevalence of mental disorders in primary care. J Affect Disord. 2004;78:49-55.

37. Knox S, Chondros P. Observed intra-cluster correlation coefficients in a cluster survey sample of patient encounters in general practice in Australia. BMC Med Res Methodol. 2004;4:30.

38. Wilde A, Meiser B, Mitchell P, Hadzi-Pavlovic D, Schofield P. Community interest in predictive genetic testing for susceptibility to major depression in a large national sample. Psychol Med. 2011;41(8):1605-14.

39. Trevena $L$, Irwig L, Barratt A. Impact of privacy legislation on the number and characteristics of people who are recruited for research: a randomised controlled trial. J Med Ethics. 2006;32(8):473-7.

40. Peay $\mathrm{H}$, Austin J. How to talk with families about genetics and psychiatric illness. New York: W.W. Norton Company Inc; 2011.

41. Weissman M, Wickramaratne P, Adams P, Wolk S, Verdeli H, Olfson M. Brief screening for family psychiatric history: the family history screen. Arch Gen Psychiatry. 2000;57:675-82

42. Meiser B, Peate M, Levitan C, Mitchell P, Trevena L, Barlow-Stewart K. A psycho-educational intervention for people with a family history of depression for use in general practice: results from pilot testing. J Genet Counsel. 2017;26:312-21.

43. Bates D, Maechler M, Bolker B, Steve W. Fitting linear mixed-effects models using Ime4. J Stat Softw. 2015;67(1):1-48.

44. Wolak ME, Fairbairn DJ, Paulsen YR. Guidelines for estimating repeatability. Methods Ecol Evol. 2012;3(1):129-37.
45. R Core Team. R: A language and environment for statistical computing. In: R Foundation for Statistical Computing: 2016.

46. Meiser B, Schofield P, Trevena L, Wilde A, Barlow-Stewart K, Proudfoot J, Peate M, Dobbins T, Christensen H, Sherman K, et al. Cluster randomized controlled trial of a psycho-educational intervention for people with a family history of depression for use in general practice. BMC Psychiatry. 2013;13(325).

47. Australian Bureau of Statistics. Socioeconomic Index for Areas (SEIFA), 2011. In: Edited by Statistics ABo; 2011.

48. Bauml J, Kissling W, Pitschelwalz G. Psychoeducational groups among schizophrenic patients: influence on knowledge and compliance. Results of the Munich PIP study. Nervenheilkunde. 1996;15(3):145-50.

49. Han DY, Chen SH, Hwang KK, Wei HL. Effects of psychoeducation for depression on help-seeking willingness: biological attribution versus destigmatization. Psychiatry Clin Neurosci. 2006;60(6):662-8

50. Quaid K, Aschen S, Smiley C, Nurnberger J. Perceived genetic risks for bipolar disorder in a patient population: an exploratory study. J Genet Counsel. 2001;10(1):41-51.

51. Morris E, Hippman C, Murray G, Michalak E, Boyd J, Livingston J, Inglis A, Carrion P, Austin J. Self-stigma in relatives of people with mental illness scale: development and validation. Br J Psychiatry. 2018;212:169-74.

52. Christensen $\mathrm{H}$, Griffiths K, Mackinnon A, Brittliffe K. Online randomized controlled trial of brief and full cognitive behaviour therapy for depression. Psychol Med. 2006:36(12):1737-46.

53. Corrigan P, Morris S, Michaels P, Rafacz J, Rüsch N. Challenging the public stigma of mental illness: a meta-analysis of outcome studies. Psychiatr Serv. 2012;63(10):963-73.

54. Kroenke K, Spitzer RL, Williams JBW: The PHQ-9. Journal of General Internal Medicine 2001, 16(9):606-613.

55. Link B: Understanding labeling effects in the area of mental disorders: An assessment of the effects of expectations of rejection. American Sociological Review 1987, 52:96-112.

56. Kasparian NA, Meiser B, Butow PN, Simpson JM, Mann GJ: Genetic testing for melanoma risk: a prospective cohort study of uptake and outcomes among Australian families. Genet Med 2009, 11(4):265-278.

\section{Ready to submit your research? Choose BMC and benefit from:}

- fast, convenient online submission

- thorough peer review by experienced researchers in your field

- rapid publication on acceptance

- support for research data, including large and complex data types

- gold Open Access which fosters wider collaboration and increased citations

- maximum visibility for your research: over $100 \mathrm{M}$ website views per year

At $\mathrm{BMC}$, research is always in progress.

Learn more biomedcentral.com/submissions 